B. TERHALLE

A.S. DESYATNIKOV ${ }^{2}$

C. $\mathrm{BERSCH}^{1}$

D. TRÄGER ${ }^{1}$

L. TANG ${ }^{1}$

J. IMBROCK ${ }^{1}$

Y.S. KIVSHAR ${ }^{2}$

C. DENZ ${ }^{1}$

\section{Anisotropic photonic lattices and discrete solitons in photorefractive media}

${ }^{1}$ Institut für Angewandte Physik and Center for Nonlinear Science (CeNoS),

Westfälische Wilhelms-Universität, 48149 Münster, Germany

${ }^{2}$ Nonlinear Physics Center, Research School of Physical Sciences and Engineering,

Australian National University, ACT 0200 Canberra, Australia

\section{Published online: 7 February 2007 • @ Springer-Verlag 2007}

Owing to an error on the part of the typesetter, an incorrect version of Fig. $5 \mathrm{c}$ was published. The correct Fig. $5 \mathrm{c}$ is given here.
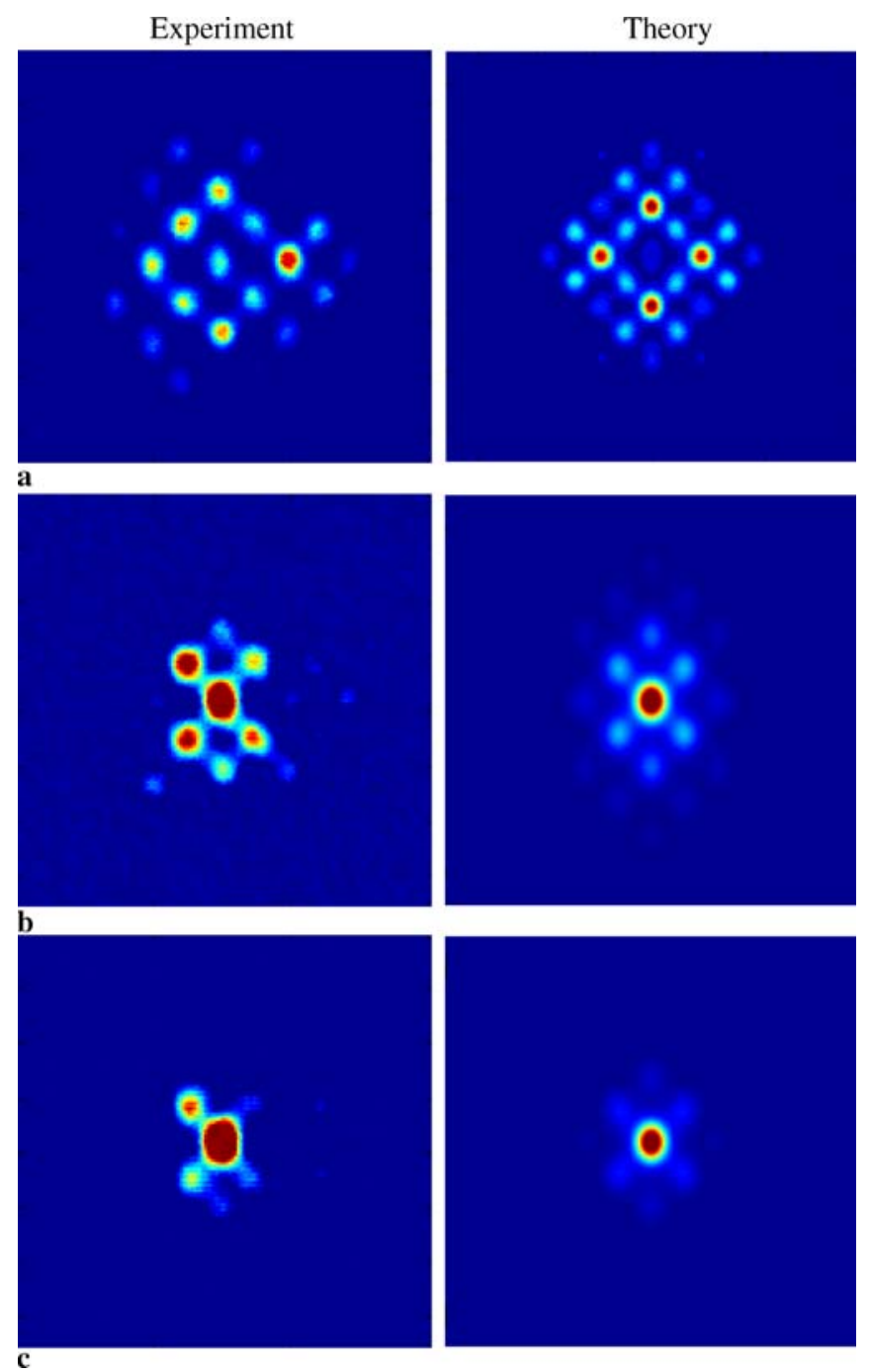

Appl. Phys. B 86 (2007)

DOI 10.1007/s00340-006-2508-3

Published online: 8 December 2006

E-mail: bernd.terhalle@uni-muenster.de

The online version of the original article can be found at http://dx.doi.org/10.1007/s00340-006-2508-3 